66

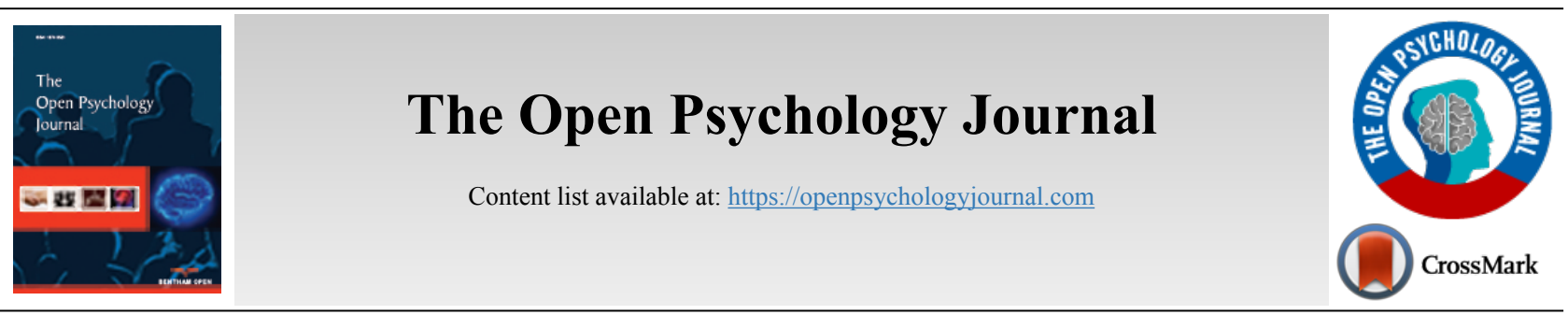

RESEARCH ARTICLE

\title{
Grade and Gender Effects on Self-Concept Development
}

\author{
Marwa Alrajhi ${ }^{1, *}$, Said Aldhafri ${ }^{1,2}$, Hussain Alkharusi ${ }^{1}$, Ibrahim Alharthy $^{1}$, Hafidah Albarashdi $^{2}$ and Amal Alhadabi ${ }^{3}$ \\ ${ }^{I}$ Sultan Qaboos University, Al-Khod, Muscat, The Sultanate of Oman \\ ${ }^{2}$ The Research Council. College of Education, SQU, Oman \\ ${ }^{3}$ Ministry of Education, 6600 Alpha Drive 240 Kent Ohio 44240, USA
}

\begin{abstract}
:
Background:

Different biological and environmental factors may play roles in the development of self-concept. Many studies have focused on gender or age differences in self-concept separately.

Objective:

The current study aimed at examining the effects of grade, gender and their interaction on the development of four self-concept dimensions (appearance, school, parent-relations, and peer-relations) among Omani adolescents.

\section{Methods:}

The study sample was 651 middle and high school students from two districts in Oman. The students were enrolled in grades 7, 9 and 11. The study utilized the Self-Description Questionnaire (SDQ-1, Marsh, 1988) to assess students' levels in the self-concepts dimensions. The study adopted the descriptive design using Two Way Multivariate Analysis of Variance.

Results:

The study results demonstrated that grade and gender interaction affected appearance self-concept development; however, this interaction had no effects on the other dimensions. Moreover, gender and grade differences were found in some dimensions of self-concept.

\section{Conclusion:}

The study suggested that the effects of grade level and gender varied based on the self-concept dimensions. Adolescents' self-concept should be given a careful attention for its important role in providing healthy outcomes.
\end{abstract}

Keywords: Students, Oman, Self-concept, Grade, Gender, Development.

\begin{tabular}{l|l|l|l} 
Article History & Received: November 19, 2018 & Revised: January 23, 2019 & Accepted: February 12, 2019
\end{tabular}

\section{INTRODUCTION}

As children grow up, they experience changes in many different aspects whether physically, psychologically, emotionally, or cognitively. These changes are the result of a combination of biological factors (i.e., maturation) and environmental factors (i.e., life experiences). This paper attempts to examine the developmental changes in Omani males' and females' selfconcept during middle and late adolescence as affected by two factors: Grade and gender.

\footnotetext{
* Address correspondence to this author at the Sultan Qaboos University, P.O Box: 35, PC. 123 Al-Khod, Muscat, Sultanate of Oman; Tel: + 96898572266; Fax: (+968) 24413522; E-mail: malrajhi36@gmail.com
}

Self-concept refers to how one perceives oneself over time. Starting in infancy and continuing throughout later ages, people construct a changing image about themselves that gradually becomes clearer and more comprehensive [1]. The changing image regarding the self is a result of both biological and environmental factors. Biological factors could be explained by the neurological processes which undergo a critical maturation during adolescence. Neurological changes in one's body partially contribute to the diversity of affective and cognitive behavior observed among adolescents [2]. On the other hand, environmental factors pertain to one's education level, lifestyle, socioeconomic status and different life experiences. Isolating environmental effects from biological effects 
are a controversial issue. In fact, both effects are integrated and can barely be isolated [3]. Both gender (biological) and grade (environmental) in particular can fundamentally influence selfconcept development.

Researchers have attempted to trace the developmental patterns of psychological variables such as self-concept within individuals. For example, cross-sectional studies are used to compare the variation in such variables between different age groups (e.g., early vs. middle childhood, or childhood $v s$. adolescence) or different school grades. Researchers have asserted that grade level is the strongest affecting variable in the development of self-concept [4]. For example, upon examining the development of four dimensions related to self-esteem and self-concept among children of different nationalities across second, fourth, sixth and eighth grades, Velasco-Barraza and Muller [5], found that as grade level increased, academic success self-esteem and self-concept became less positive. However, Alawiye and Alawiye [4] indicated that self-concept increased across grades. Similar findings were reported by longitudinal studies which examined individual developmental changes over time [6].

Very little research, if any, to our knowledge, has examined the development of self-concept in the Omani context. Without doubt, culture has a great role to play in any pattern of development. Arabic culture has its own distinguished norms and values that affect the way its people develop which is likely different from the other cultures. Therefore, the current study is important as it highlights the effects of grade and gender, and their interaction in the development of four dimensions of self-concept (general school, peer-relations, parentsrelations, and appearance) among early and middle adolescents (grades 7, 9, 11) in the Sultanate of Oman.

\subsection{Psychosocial Development Theory and Self-Concept}

Early theories of psychosocial development, such as Erikson's theory, implied the importance of social interactions in one's cumulative understanding of the self, which usually fall into different dimensions. Erikson proposed eight psychosocial obstacles that a child goes through as a result of social interactions. Each obstacle contributes to the development of the child's identity or self. For example, one of these obstacles that is experienced during adolescence is "identity $v s$. identity confusion" in which the adolescent tries to answer the question "who am I?" and adopts different kinds of identities. These types of obstacles continue until later ages when people either arrive at "identity achievement" and feel satisfied about their past life or reach a stage of desperation due to a feeling of underachievement in their lives [7].

In 1976, Shavelson, Hubner, and Stanton [8] developed self-concept theory in which they suggested that self-concept has two main characteristics: (1) It is multifaceted in that it has different dimensions, (2) It is hierarchal with general selfconcept placed at the top of the hierarchy (first level) followed by both academic and non-academic self-concept (second level). In the third level, various dimensions of academic selfconcept (e.g., language, math, science, history) and non-academic self-concept (i.e., emotional, physical, and social selfconcept) are placed. In addition to those two main character- istics of self-concept, Shavelson's et al. [8] model also explained that self-concept dimensions become more differentiated as one grows up. A number of studies have been conducted examining the model presented by Shavelson et al. and they are generally in agreement with the findings [e.g., 9; $10]$.

\subsection{Self-Concept Definition}

Several attempts have been made by researchers to illustrate what self-concept is; yet, almost all of them are concerned with the understanding or perceptions of oneself. According to Baby [11], self-concept reflects someone's feelings or perceptions about himself including self-assessment of physical attributes, hobbies, skills, abilities and personality. It is like a set of beliefs people have about who they are; involving personal, ethnic, and professional awareness as well as other future goals or desire. Likewise, Krishnakar and Chengti [12] defined self-concept as the "accumulation of knowledge about the self" (p. 2) and they stated that beliefs and evaluations individuals make about themselves indicate not only what they think about themselves but also what they think they can become in the future.

Self-concept can be referred to as a general self or general self-worth, and it can be measured using specific dimensions. For instance, Marčič and Grum [13] suggested that selfconcept dimensions can be classified into independent and interdependent self-concept. Independent self-concept comprises elements of oneself such as physical appearance, education, goals, intelligence and abilities. On the other hand, interdependent self-concept represents one's relationships with others such as peers and family. Based on Shavelson et al's [8] suggestion that self-concept is best measured in more specific dimensions that characterize different aspects of one's life, the present study focused on measuring specific dimensions of self-concept (general school, peer-relations, parents-relations, and appearance) rather than the general self.

\subsection{How Does Self-Concept Develop?}

As noted earlier, Shavelson et al's [8] model suggests that self-concept dimensions become more differentiated as one grows up. It is crucial to know that the first stage of development of self-concept starts in infancy when the infant recognizes himself as one individual. Early in infancy, children acquire information about themselves and organize this information as a means to understand the world and their relationships with the social environment [14]. Baby [1] explained that in childhood, children's self-concept is "less differentiated" and it is concerned with tangible characteristics such as skills, possessions and physical attributes. On the other hand, during middle childhood, self-concept becomes more differentiated and integrated. It becomes more internal as the child starts to interact with different social relations. In fact, there is a possibility that self-concept may undergo some changes even during middle or late adulthood, for example, Mansoor [15] found significant differences in self-concept across early adulthood, middle age, and old age.

According to Baby [1], the formation of self-concept goes through four stages: (1) in infancy, the infant develops self- 
concept of being a distinguished part of the environment, (2) as the child grows up, others' perspectives, especially parents', are internalized and (3) finally, moving from parents' perspectives, the child internalizes society norms (e.g., expected appropriate behaviors). One can conclude that multiple factors contribute to the reshaping of self-concept as individuals age. For example, consistent feedback from parents is considered a primary source of forming self-concept among children; however, as they grew up to become teenagers, they become more reliant on their peers' opinions and peers' perceptions become an important source of self-concept for adolescents. In addition, Kawkash [16] explained some other factors contributing to a person's self-concept such as gender, attitudes, physical appearance and confidence.

Adolescence is considered a very critical period of time in which an individual goes through various physical and psychological changes that most probably influence his/her selfconcept. If parents and teachers are able to understand the changes that occur during adolescents' self-concept formation, they may be able to help them adjusting to these changes [16]. Furthermore, early adolescence has been recognized as a developmental phase in which peer relationships become more salient while family relationships become weaker [17]. Therefore, focusing self-concept research on this stage of development is very important.

Self-concept may become more positive or negative as individuals grow up. The change in self-concept is dependent on its specific dimensions. For instance, Shapka and Keating [6] examined the developmental change of different selfconcept dimensions among school students (grades 9-12) over a two-year period. The researchers found that students had more positive self-concept as they grew up in dimensions of job competence, romantic relationships, close friendships, and social acceptance. On the other hand, over the course of their time at high school, students' perceptions about scholastic competence declined. Also, according to Marsh [11], Australian students' appearance, physical and academic self-concepts reduced by the largest margin in moving from grade two to grade eight.

It is clear that there have been several studies addressing self-concept development in Western cultures. However, there may be critical differences when examining a collective Arabic culture such as that found in the Sultanate of Oman. It is, therefore, crucial to explore the developmental patterns of selfconcept in such a context.

For example, Smoaay [18] showed that general selfconcept for Iraqi children increased from age 5 to 7 years old. Also similar to Shapka and Keating [6] who found increased self-concept in dimensions of social acceptance and close friendship, Gamer [19] showed that social self-concept among undergraduate Sudanese students increased as they got older. However, another Arabic study conducted by Saber [20] using adolescents aged 12 to 18 , social self-concept was positively correlated with age during middle school but negatively during secondary school. Moreover, in another study involving students from elementary school and junior high school students in the UAE, the findings showed that elementary school students scored higher in math self-concept and school self-concept than high school students [21] which was consistent with the findings by Shapka and Keating [6] related to scholastic competence self-concept.

While these studies have demonstrated some differences in self-concept dimensions for different age groups, others found no differences. For example, Chang et al. [17] found no statistical differences in social and general self-concept between children and adolescents. Moreover, Adeeb [22] examined gene-ral self-concept development among Omani students during late childhood, grade six (age:11-12) and early adolescents, grade 9 (age:15-16). The researcher found no evidence for self-concept development between these two periods. Also, Shapka and Keating [6] did not uncover any cross-sectional change between grade 9 and 10 in different self-concept dimensions.

A number of studies was conducted to examine gender effects on self-concept development. For example, Alrajhi and Aldhafri [23] found that Omani girls scored higher on academic English self-concept than boys did; yet, no differences in social self-concept were reported. In another study, Omani girls were also found to have higher math and verbal self-concept than boys [24]. However, contradictory results have been documented in other studies. Marsh et al [as cited in 25] found that in four Arab countries, boys reported more positive science and math self-concept than girls. Likewise, Gamer [19] reported that Sudanese male students showed higher academic and social self-concept than female students.

It seems that all previous studies have examined gender differences in self-concept separately from the effect of age. However, possible differences in the development of selfconcept by age may appear across gender. A substantial amount of literature has shown that males and females may follow different patterns in their self-concept development. For instance, a significant interaction was found between time and gender in general self-worth across a two year period of time (from grade 9-10 to grade 11-12). Unlike girls, boys' levels of self-worth dropped off over the course of time. Moreover, boys did not only show lower levels of close friendships selfconcept than girls but also this level increased only during late high school. On the other hand, girls' levels of self-concept in this domain increased both during early and late high school [6]. In addition, over a three-year period of time (from grade 1 to 3), Bouffard, Marcoux, Vezeau, and Bordeleau [26] found that although both boys' and girls' perceptions of reading competence decreased across time, the decrease started earlier for boys than girls.

Hence, it is vital to examine how boys' and girls' selfconcepts develop over the course of time. The current study uses a statistical design that allows the examination of the interaction between gender and age effects.

\subsection{Cultural Similarities and Variations}

Self-concept develops as the individual interacts with his/her environment. As different cultural environments exist, it is expected that different patterns of self-concept will be developed by individuals [4]. The development of self-concept depends on the nature of the society; whether it is an individualistic or a collective (i.e., communal) society. Triandis [27], has 
gradeified cultures as individualistic or collective cultures. While individualism focusses on one's independence as a way of life, collectivism focuses on one's centering on the group as a way of life. Unlike collective societies, people in individualistic societies tend to be more competitive and value individual attributes more than collective attributes, or group identities such as family, community or religion [3]. Therefore, individualists have higher levels of positive self-concept than collectivists because they tend to exaggerate in order to reinforce their self-worth and draw attention to themselves [27].

Some studies in Western (individualistic) societies suggested similar patterns of self-concept development. For example, Nagy et al. [28] found that in all three countries included in the sample (Australia, The United States, Germany), a major decline in academic self-concept was evident across the different grade levels (from 7 to 12). In another cross-cultural study conducted in Mexico, Chile and the United States, researchers found that physical maturity and peer-relations self-concept was relatively stable across grades $(2,4,6,8)$; however, as grade level increased, the levels of academic success self-concept and school adaptiveness self-concept decreased [5].

Abu Hilal [27] stated that cross-cultural studies have shown that East-Asian individuals look at themselves in a communal or societal framework and it is difficult for them to view themselves as distinct from this framework. An Arab individual is not very different from an East-Asian in the way they look at themselves. Thus, the success one achieves is looked at in terms of how it serves the group more than the individual. The communal nature of collective societies suggests that in collective societies such as Oman, social selfconcept (i.e., family, peer- relations) is very important as children grow up. This was posited by Abu-Hilal et al. [25], who suggested that the role of significant others in self-concept formation can be more important in Arab-Muslim cultures than in others. Unfortunately, there is a notable lack of research examining the development of different self-concept dimensions in the Arab context. The current study will contribute to the existing literature regarding this area. Also, it adds to Adeeb's [22] study, which focused only on general self-concept development among Omani students across late childhood to early adolescence. The current study examined the development of four self-concept dimensions (general school, peerrelations, parents-relations, and appearance) among early and middle adolescence across gender. Finally, findings of this study allow comparisons between Omanis' self-concept development patterns, which is considered a collective society, and other Western and Eastern cultures.

\section{METHODOLOGY}

\subsection{Sample}

The sample consisted of 651 middle and high school students from two school districts (i.e., Aldakhliya and South Batinah) in Oman. The students were enrolled in grades 7, 9, and 11; half of the sample were males $(50.50 \%)$. Students' ages ranged from 12 to $17(M=14.51, S D=1.49)$. Permission for data collection was obtained from the Ministry of Education and the local school district. All contacted schools agreed to participate in the study. Two research assistants visited convenient samples of schools and administered the self-concept questionnaire. Some demographic information was also obtained from the participants including age, grade, and gender.

\subsection{Measures}

The participants responded to the Arabic version of the Self-Description Questionnaire (SDQ-1) [11]. The questionnaire originally includes 67 items that measure different dimensions of self-concept including general school, academic, peer relationships, physical ability, physical appearance, and parent relationships. A 5-point Likert scale questions are used (i.e., False, Mostly false, Sometimes true / Sometimes false, Mostly true and True); the higher the score, the higher the level of each dimension. Early Arabic research showed good reliability coefficients for the questionnaire in the Omani context $[23,29]$. In the current study, we used four dimensions that repre-sent general school ( $\alpha=0.87,8$ items, e.g.,: "I'm excellent in all school subjects"), appearance ( $\alpha=$ $0.82,8$ items, e.g., "I have a beautiful body"), parents relationships ( $\alpha=0.80,8$ items; e.g., "I love my parents"), and peer relationships ( $\alpha=0.84,8$ items, e.g., "I have lots of friends"). All items were positively scored (no reverse scored items). Construct validity for the questionnaire was obtained by a pre-specified four-dimension solution using maximum likelihood as an extraction method with a Promax rotation. The results showed a very clear 4-factor solution with all items loading in their perspec-tive theoretical dimensions with loading values equal to 0.30 or above.

\section{RESULTS}

Prior to data analysis, MANOVA assumptions were tested. First, multivariate normality was examined. According to Tabachnick and Fidell [30] "robustness" should be ensured by having a sample size of at least 20 in each cell. The sample size in the current study included more than 20 individuals in each comparison group (i.e., male and female, grades 7, 9 and 11). Moreover, skewness and kurtosis of the self-concept at each level of the independent variables (gender and grade) were used to check multivariate normality. Skew-ness values all conformed to the accepted values (-2 to 2) as did kurtosis (accepted values of -7 to 7 ). Second, linearity between each pair of the dependent variables was checked using matrix scatterplots which showed the existence of a linear relationship in each cell.

Third, multicollinearity was examined by finding the bivariate correlations between the dependent variables in all sets of comparison groups. All correlation coefficients were found to be significant and less than 0.80 which suggests moderate correlations between the dependent variables, thus multicollinearity doesn't exist. Fourth, homogeneity of the variancecovariance matrix was examined using Box's M Test. Box's M Test value was found to be significant $(F=2.37, p>0.001)$ which suggests the equal variance cannot be assumed. Therefore, Pillai's trace is used as the test statistic.

Two-way MANOVA $(2 \times 3)$ was used to examine the effects of gender and grade on self-concept dimensions (appea- 
Table 1. Descriptive statistics of self-concept dimensions based on class and gender.

\begin{tabular}{|c|c|c|c|c|c|c|c|c|c|c|c|c|}
\hline Variables & \multicolumn{1}{|c|}{ Appearance Self-Concept } & \multicolumn{1}{c|}{ School Self-Concept } & \multicolumn{3}{c|}{ Parents Relations Self-Concept } & \multicolumn{2}{|c|}{ Peer Relations Self-Concept } \\
\hline Gender & $N$ & $M$ & $S D$ & $N$ & $M$ & $S D$ & $N$ & $M$ & $S D$ & $N$ & $M$ & $S D$ \\
\hline Males & 329 & 3.87 & 0.65 & 329 & 3.48 & 0.71 & 329 & 4.17 & 0.58 & 329 & 3.71 & 0.70 \\
\hline Females & 322 & 4.10 & 0.54 & 322 & 4.08 & 0.58 & 322 & 4.32 & 0.61 & 322 & 4.00 & 0.69 \\
\hline Class & - & - & - & - & - & - & - & - & - & - & - & - \\
\hline 7 & 233 & 4.16 & 0.63 & 233 & 3.89 & 0.71 & 233 & 4.35 & 0.54 & 233 & 3.92 & 0.75 \\
\hline 9 & 184 & 4.04 & 0.66 & 184 & 3.64 & 0.77 & 184 & 4.18 & 0.61 & 184 & 3.86 & 0.70 \\
\hline 11 & 234 & 4.09 & 0.64 & 234 & 3.76 & 0.67 & 234 & 4.19 & 0.62 & 234 & 3.79 & 0.68 \\
\hline
\end{tabular}

Table 2. Multivariate tests for differences in self-concept based on class, gender and their interaction.

\begin{tabular}{|c|c|c|c|c|c|c|}
\hline Source & Pillai's Trace & F & df & Error df & $\boldsymbol{p}$ & Eta Squared \\
\hline Class & 0.02 & 2.09 & 8 & 1286 & 0.03 & 0.013 \\
\hline Gender & 0.19 & 39.63 & 4 & 642 & 0.00 & 0.198 \\
\hline Class*Gender & 0.05 & 4.55 & 8 & 1286 & 0.00 & 0.028 \\
\hline
\end{tabular}

Table 3. Univariate ANOVA summary effects.

\begin{tabular}{|c|c|c|c|c|c|c|}
\hline Source & Sum of Squares & $d f$ & Mean Square & $F$ & $p$ & Eta Squared \\
\hline- & \multicolumn{6}{|c|}{ Appearance self-concept } \\
\hline Class & 0.42 & 2 & 0.21 & 0.58 & 0.556 & 0.002 \\
\hline Gender & 31.93 & 1 & 31.93 & 88.96 & 0.000 & 0.121 \\
\hline Class*Gender & 3.47 & 2 & 1.78 & 4.84 & 0.008 & 0.015 \\
\hline Error & 231.53 & 645 & - & - & - & - \\
\hline- & \multicolumn{6}{|c|}{ School self-concept } \\
\hline Class & 2.54 & 2 & 1.27 & 2.98 & 0.051 & 0.009 \\
\hline Gender & 51.12 & 1 & 51.12 & 119.74 & 0.000 & 0.157 \\
\hline Class*Gender & 3.34 & 2 & 1.67 & 3.91 & 0.020 & 0.012 \\
\hline Error & 275.39 & 645 & - & - & - & - \\
\hline- & \multicolumn{6}{|c|}{ Parents relations self-concept } \\
\hline Class & 3.27 & 2 & 1.63 & 4.69 & 0.009 & 0.014 \\
\hline Gender & 2.36 & 1 & 2.36 & 6.75 & 0.010 & 0.010 \\
\hline Class*Gender & 2.28 & 2 & 1.14 & 3.266 & 0.039 & 0.010 \\
\hline Error & 225.32 & 645 & - & - & - & - \\
\hline- & \multicolumn{6}{|c|}{ Peer relations self-concept } \\
\hline Class & 1.73 & 2 & 0.86 & 1.77 & 0.170 & 0.005 \\
\hline Gender & 13.10 & 1 & 13.10 & 26.82 & 0.000 & 0.040 \\
\hline Class*Gender & 2.53 & 2 & 1.26 & 2.59 & 0.076 & 0.008 \\
\hline Error & 315.11 & 645 & - & - & - & - \\
\hline
\end{tabular}

rance, school, peer, and parent). Table 1 shows the descriptive statistics of each self-concept dimension based on grade and gender. In addition, Table 2 shows the multivariate analysis results indicating that there were statistically significant multivariate differences in self-concept attributed to the interaction between gender and grade $(p<0.001$, Pillai's trace $=$ $0.055)$. The effect size indicated that $2.8 \%$ of the variance in self-concept is explained by the interaction between gender and grade.

Bonferroni adjustment of alpha was used in tests of between subject effects and the multiple comparisons test; comparisons were made at an alpha level of 0.012 . The results showed that there were statistically significant differences in appearance self-concept attributed to the interaction between gender and grade $(p=0.008)$. The effect size showed that $1.5 \%$ of the variance in appearance self-concept is explained by the interaction between grade and gender (Table $\mathbf{3}$ ). This value is considered a small effect according to Cohen's accepted criteria [31]. Interaction plots showed that female students had higher levels of appearance self-concept in the all three grades (grade 7, 9, and 11) than male students (Fig 1). Females' appearance self-concept tended to decrease as they move from grade 7 to 9; however, it tended to increase again as they move from grade 9 to 11 . On the other hand, males' appearance selfconcept seemed almost stable before it started to steadily decrease as they move from grade 7 to grade 11 . 


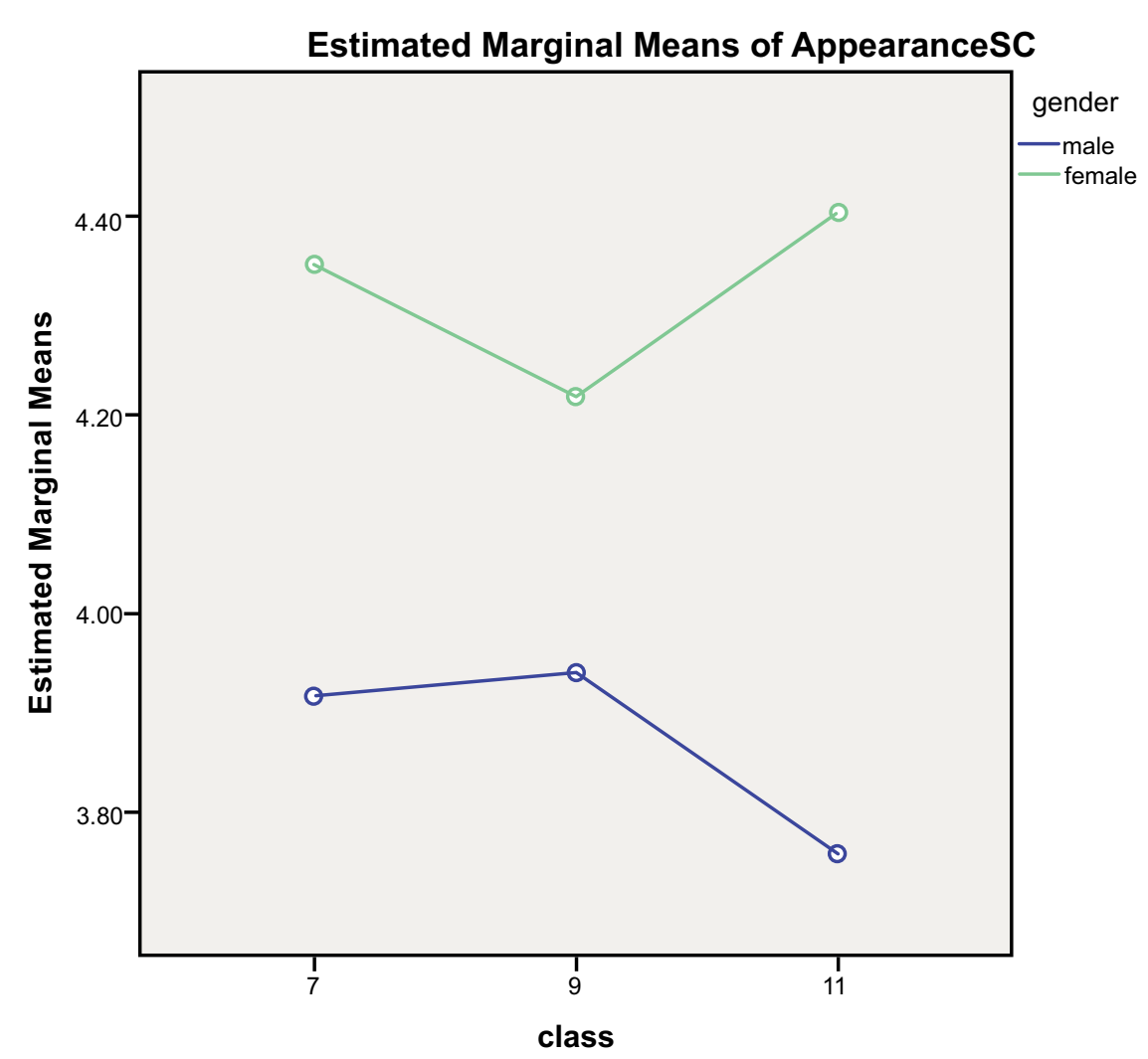

Fig. (1). Interaction between class and gender in appearance self-concept.

The interaction between gender and grade was not significant in the other dimensions of self-concept. Moreover, there were statistically significant gender difference in school $(p=$ 0.000 , effect size $=15.7)$, parent $(p=0.010$, effect size $=1 \%)$ and peer self-concepts $(p=0.000$, effect size $=4 \%)$; with all effect size values showing small effects according Cohen's accepted criteria [31]. Female students had higher levels of self-concept in these three dimensions than male students. In addition, statistically significant grade differences were found in parent self-concept $(p=0.009)$. The effect size showed that $1.4 \%$ of the variance in parent self-concept was explained by the grade effect which is also considered a small effect [31]. Multiple comparisons tests showed that as grade level increased, parent self-concept decreased; that is, grade 7 students had higher levels of parent self-concept than grade 9 students. In the same way, grade 9 students had higher levels of parent selfconcept than grade 11 . No significant grade differences were found in peer or school self-concepts.

\section{DISCUSSION}

The current study aimed at examining the development of four self-concept dimensions (general school, peer-relations, parent-relations, and appearance) among early and middle adolescents (grades 7,9 and 11) across gender. As previously discussed, previous research has proved that males and females may follow different or similar patterns of self-concept development as they grow up $[6,26]$. The current study showed that the interaction between grade and gender had statistically significant effects on overall self-concept develo-pment. Effect size showed that $2.8 \%$ of the variance in the overall selfconcept was explained by the interaction between grade and gender. This suggests other variables may play a role in selfconcept development such as the effects of significant others including peers, parents and teachers [1,22].

A closer look at self-concept dimensions; however, reveals that grade and gender interaction was not significant for three dimensions (school, parent-relations, and peer-relations selfconcepts); it was actually only significant for appearance selfconcept. The results demonstrated that overall, females had higher levels of self-concept across the three grades than males. Male students' appearance self-concept was almost stable between grades 7 to 9 , but it noticeably decreased as they moved from grade 9 to 11 . This suggests that as male students grow up, they tend to have lower positive self-concept about their appearance. In contrast, female students' appearance self-concept followed an inconsistent pattern across the three grades. Females' appearance self-concept tended to decrease as they move from grade 7 to 9 ; yet, it increased again as they move to grade 11. In contrast with the current findings, a Canadian study showed that gender and time interaction was not significant for appearance self-concept; and girls manifested lower levels of appearance self-concept than boys across grades (grades 9 to 12) [6]. Similarly, Marcotte, Fortin, Potvin, and Papillon [32] reported that among Canadian adolescents (aged 11-18 years old), girls showed less positive body-image perceptions than boys.

It should be noted that, unlike Oman, the participants in these studies came from mixed gender schools. Peer pressure 
might be different between same-gender peers or different gender peers. Girls might be affected by their male peers' views that males have stronger and more graceful bodies. As suggested by Shapka and Keating [6] societal and scholastic efforts should be made to counteract the negative messages girls receive about their bodies from other social agents. Of course, gender influence is mostly absent inside adolescents' schools in Oman as they are all single sex.

However, the reason why Omani females in the current study demonstrated an inconsistent pattern of appearance selfconcept development might be attributed to several reasons. Grade 7 students are still young and perceive themselves as being attractive. Hudson [33] explained that children of both genders start with high positive levels of self-esteem that start to diminish as they move from elementary school to middle or high school. However, after this stage, pubertal changes start to appear clearly in girls. Younger girls (i.e., grades 7-9) are still at their early stages of pubertal changes which negatively influence their appearance self-concept. As girls age, selfconcept becomes clearer and more differentiated $[1,8]$. Therefore, as female students move to grade 11, they are most likely to have a better understanding of their body-image and they can more accurately and confidently reveal their true appearance self-concept.

Another reason is that girls are influenced by their female peers' feedback and body-image. They compare themselves with their peers which can make them feel unsatisfied with their appearance because they think that their peers are prettier than them. Numerous studies have shown the influence of peer feedback on adolescent girls' body image [34, 35].

Much research has focused on female appearance selfconcept $[34,35]$. However, male appearance self-concept has been rarely addressed. Consistent with previous studies which reported that females manifest higher levels of positive body image (appearance self-concept) than males [36, 37], the current study also revealed that male students' manifested lower levels of appearance self-concept in all three grades (7, 9 and 11). In addition, the level of their appearance self-concept continues to decrease as they grow up. During this period of their life male adolescents like to spend much of their time outside their homes playing with their peers, practicing different types of sport and other activities. Thus, they are more susceptible to injuries and various physical confrontation than females. As a result, they might form negative perceptions of their appearance [38]. Moreover, often adolescent boys are given less attention associated with their physical appearance by their families than girls are. Boys prefer to take care of themselves and they often don't want their parents to interfere. On the other hand, parents, especially mothers, make sure that their girls look tidy and pretty to others. This attention could be due to girls approaching marriageable age at this time. These interpretations, however, need to be validated by future research. Furthermore, Leone et al. [38] found that there are various causes for male body image dissatisfaction such as bullying, having fewer friends, coping with criticism from parents and siblings, a desire to have the body of another person, and the use of drugs.
There is a clear inconsistency in the literature regarding appearance self-concept development across age and gender. Moreover, since very scarce research has focused attention on age and gender interaction effects on appearance self-concept, conclusions as to whether Omani students are following global or cultural-specific patterns of development in this dimension cannot be made.

Appearance self-concept, or so called body-image, was found linked to different well-being outcomes among adolescents such as depression $[32,36]$, self-esteem and stress [36], and life satisfaction [39]. Therefore, it is recommended that early interventions (e.g., training or self-reinforcement programs) should be executed by schools and families for adolescents during this time to avoid negative outcomes. Taking consideration of students' appearance self-concept is very important. Parents and teachers need to give positive messages for the students regarding their appearance and limit criticisms because this might negatively affect their mental health as well as their academic well-being. Also, school environments should be well prepared to confront the strong effects of media on students' appearance self-concept.

The study findings also indicated that there were no interaction effects between age and grade on the other three dimensions of self-concept (school, parent-relations, and peerrelations self-concept). However, there were statistically significant gender differences in school, parent, and peer selfconcepts, all of which revealed that female students have higher levels than male students. The Finding regarding school self-concept is consistent with previous research that reported higher school self-concept among females than males [e g., 37]; similar studies conducted with Omani adolescents uncovered the same result $[23,24]$.

Several reasons could be behind the high levels of school self-concept among females. Adeeb [22] explained that Omani females started to receive education at a much later time than males did. It was not until Sultan Qaboos came to power in 1970 in Oman that females were allowed to attend school. This was a momentous step by the government to encourage females to gain an education. Thus, Omani female students started school with a strong passion to learn which positively influenced their self-concept. Motivation has been found in multiple studies to exert a strong effect on school self-concept $[40,41]$. Previous Arabic studies have shown that female students had higher levels of motivation to learn than male students did $[42,43]$. Similarly, Omani female students were found to have higher levels of motivation than male students. For example, Alharthy and Aldhafri [44] found that Omani female students scored higher than male students in both academic self-efficacy beliefs and task value. Academic achievement has a great role as well. A national project that focused on understanding the gap between Omani male and female students confirmed this achievement gap, with females outperforming males across different grades starting in elementary grades up to university level [45]. The researchers attributed this gap to a collection of variables including student motivation, study skills, socialization, and communication. Also, national TIMMS reports have revealed that Omani female students, in both grades 4 and 8 , performed higher than their male counterparts [46, 47]. 
Previous studies $[5,6,21]$ have suggested that as students grow up, the levels of their school self-concept decreased. In contrast to these findings, the current study found no significant effects of grade on school self-concept. It is difficult to understand this trend in the current study using the available data. The researcher speculates, however, that these nonsignificant effects can be attributed to the effects of other intervening un-examined variables including cognitive, motivational, and behavior characteristics of the current sample. Future research may shed light on these findings using a comprehensive study model.

In line with the current results, other studies have proved lower levels of social self-concept such as peer and closefriendship among boys in contrast to girls $[5,6]$. Although, Alrajhi and Aldhafri [23] found insignificant gender differences in Omani eight graders' social self-concept (including both parent and peer self-concept items), which is inconsistent with the current findings. However, their examination of both parent and peer self-concepts as one variable (social self-concept) could have confounded the possible gender differences.

Unlike previous studies which suggested that grade (or age) has effects on peers (or social self-concept) [e.g., 6; 20], the current study found no significant effects of grade on peer self-concept. For example, social self-concept was found positively correlated with age during middle school but negatively during secondary school [20]. Also, Shapka and Keating [6] reported increasing levels of close friendship selfconcept with age (grades 9 to 12), although for boys, the increase was only clear for the last two years of high school.

The current finding is similar to Chang et al. [17] who found no significant differences in social self-concept between children and adolescents, although it should be noted here that the current study is investigating adolescence only. The absence of differences in peer self-concept between the three grades $(7,9$, and 11$)$ can be explained by the nature of the collective society we have in Oman. As noted previously in the literature, collective societies usually appreciate social relationships and group connectedness [27]. Regardless of their ages, students in Oman usually have good connections with their peers and positively perceive their social relationships with them. However, generalizations cannot be made at this point and investigations into different age groups (such as children, adolescents, and adulthood) is crucial.

In addition, this result is in line with Velasco-Barraza's and Muller's [5] findings that peer self-concept remained stable across grades $(2,4,6$, and 8 ) across three different cultures (Mexico, Chile and the US). It can be noticed that Omani adolescents followed the same pattern as these Western cultures as the levels of peer self-concept did not change with age. Therefore, cross-cultural research between Oman and other Eastern and Western cultures should be considered to examine the pattern that peer self-concept follows across different cultures.

Turning to gender differences in parent relation selfconcept. Similar to the current findings, some studies on parent self-concept (or family self-concept) have also found that female students have higher levels than male students [5]. Girls are generally assumed to have better communication and relationships' building skills which facilitate their social interaction and positively influences their social self-concept.

Additionally, the current findings suggested significant effects on parent relations self-concept based on grade level. The findings revealed that grade seven students had higher levels of parent self-concept than grade nine students; also, grade nine students had higher levels of parent self-concept than grade eleven which suggests that as students grow up, they tend to have lower levels of parent self-concept. These findings are in line with Omani research related to parenting styles carried by Aldhafri and his colleagues [48, 49]. Older students were more likely to perceive their parent demands as being authoritarian and authoritative parenting styles compared with younger students. Students in higher grades resenting their parents' control might be reflected in their lower levels of parent self-concept found in the current study.

Although it has been suggested that during adolescence parent relations become weaker while peer relations become stronger [17], the current study's findings support the suggestion that parent self-concept becomes weaker as students grow up, but they don't support the assum-ption that peer selfconcept becomes stronger, since no differences in peer selfconcept with grade level were found. The dimension of parent self-concept (or so-called family self-concept) is rarely studied in the literature. In contrast to parent self-concept, many studies have examined social self-concept which usually considers peer relation as a major part of it. Future research should direct more attention on parent self-concept development. Comparison between peer and parent selfconcept developmental patterns may provide a better understanding of adolescents' social development and the importance of significant others in different developmental stages. Significant others play a major role in Arab-Muslim individuals' self-concept [25].

\section{CONCLUSION}

To sum up, the development of four dimensions of selfconcept (i.e., general school, peer-relations, parent-relations, and appearance) across grade level and gender were examined in this study. It has been approved that male and females may develop different levels of self-concept as they grow up. Appearance self-concept was the only dimension affected by the interaction of grade and gender. Grade or gender differences in other dimensions of self-concept (i.e. general school, peer-relations, parent-relations) were also found.

The current study has some limitations. First, the study utilized a cross-sectional design to detect self-concept development. Further studies need to consider Omani students' selfconcept development using a longitudinal approach which was found to be more effective in detecting possible developmental changes in self-concept dimensions than cross-sectional approaches [6]. Following up with the current sample after a two year period may provide different findings of self-developmental patterns. Second, the current study focused only on adolescence; hence, investigation of self-concept dimensions across different developmental stages (for example, childhood to 
adulthood) or educational stages (for example, from primary to high school) is important. Third, cross-cultural studies that compare between Oman and other Western and non-Western countries can provide a more thorough understanding of selfconcept development in relation to cultural effects.

The current study has certain implications for students, schools, and parents. Training programs should be organized for students to reinforce their positive feelings about themselves, strengthen their positive self-concept, and assist them to reach a better understanding of themselves. Not only should students be targeted by such programs but also awareness raising programs should be implemented for teachers, school social workers and parents regarding psychological variables related to students, including self-concept. These agents, if properly trained, are in the best position to deal with students effectively and help them to develop a positive self-concept in different dimensions. Therefore, collaborative efforts should be exerted by various stakeholders such as the Ministry of Education, school administrations, social workers or counselors, and parents to improve and sustain students' mental health.

\section{ETHICS APPROVAL AND CONSENT TO PARTICI- PATE}

Not applicable.

\section{HUMAN AND ANIMAL RIGHTS}

No animals/humans were used for studies that are the basis of this research.

\section{CONSENT FOR PUBLICATION}

Not applicable.

\section{CONFLICT OF INTEREST}

The authors declare no conflict of interest, financial or otherwise.

\section{ACKNOWLEDGEMENTS}

Declared none.

\section{REFERENCES}

[1] Baby S. Development of self-concept and health. Soc Sci Int 2012; 28(2): 253-63.

[2] Yurgelun-Todd D. Emotional and cognitive changes during adolescence. Curr Opin Neurobiol 2007; 17(2): 251-7. [http://dx.doi.org/10.1016/j.conb.2007.03.009] [PMID: 17383865]

[3] Shaffer D, Kipp K. Developmental psychology: Childhood and adolescence. Unites States: Cengage Learning international Offices $2015.8^{\text {th }}$ ed

[4] Alawiye O, Alawiye C. Self-concept development of Ghanaian school children. J Psychol 2001; 122(2): 139-45. [http://dx.doi.org/10.1080/00223980.1988.9712699]

[5] Velasco-Barraza C, Muller D. Development of self-concept in Chilean, Mexican, and United States school children. J Psychol 1982; 110: $21-30$.

[http://dx.doi.org/10.1080/00223980.1982.9915321]

[6] Shapka J, Keating D. Structure and change in self-concept during adolescence. Can J Behav Sci 2005; 37(2): 83-96. [http://dx.doi.org/10.1037/h0087247]

[7] Adas A. Educational Psychology: A contemporary look Amaan: Alfikir House for Printing. Publishing, and Distribution 1998.

[8] Shavelson R, Hubner J, Stanton G. Self-concept: Validation of construct interpretation. Rev Educ Res 1976; 46(3): 407-41. [http://dx.doi.org/10.3102/00346543046003407]

[9] Marsh H, Shavelson R. Self-concept: Its multifaceted, hierarchical structure. Educ Psychol 1985; 20(3): 107-23.

[http://dx.doi.org/10.1207/s15326985ep2003_1]

[10] Marsh H. The structure of academic self-concept: The Marsh/Shavelson Model. J Educ Psychol 1990; 82(4): 623-36. [http://dx.doi.org/10.1037/0022-0663.82.4.623]

11] Marsh HW. Age and sex effects in multiple dimensions of selfconcept: Preadolescence to early adulthood. J Educ Psychol 1989; 81(3): 417.

[http://dx.doi.org/10.1037/0022-0663.81.3.417]

[12] Krishnakar M, Chengti S. Self-concept in secondary school students. Golden Res Thoughts 2012; 2(6): 1-7.

13] Marčič R, Grum D. Gender differences in self-concept and self-esteem components. Stud Psychol 2011; 53(4): 373-84.

[14] Burns R. Self-concept development and education. London: Holt, Rinehart and Winston 1982.

[15] Mansoor A. The elderly's self-concept. J King Saud Univ Educ Sci 1989; 1(1, 2): 223-67.

[16] Kawkash H. Adolescents' self-concept. Teachers'. Message J 1978; 21(4): 50-6.

[17] Chang L, Chang C, Stewart S, Au E. Life satisfaction, self-concept, and family relations in Chinese adolescents and children. Int J Behav Dev 2003; 27(2): 182-9.

[http://dx.doi.org/10.1080/01650250244000182]

[18] Smoaay F. The development of self-concept in children. Teach 2018; 224: 293-316.

[19] Gamer M. Human self-concept among Dongla university students in the light of some variables. Soc Sci J 2018; 46(1): 110-38.

[20] Saber W. Adolescents' self-concept development in terms of cultural and social variables. Family counseling and society developmen towards wide counseling outlooks Proceeding of 15th Annual Conference. 847-78.

[21] Abu-Hilal M, Bahri T. Self-concept: The generalizability of research on the SDQ, Marsh/Shavelson model, and I/E frame of reference model to United Arab Emirates Students. Soc Behav Personal 2000; 28(4): 309-22.

[http://dx.doi.org/10.2224/sbp.2000.28.4.309]

[22] Adeeb A. Self-concept development among children and adolescents of both genders and its relationship with academic achievement. Psychol -Egypt 1991; 6(20): 100-17.

[23] Alrajhi M, Aldhafri S. Academic and social self-concept: effects of teaching styles and gender in English as a foreign language setting. J Psychol Afr 2015; 25(1): 44-9. [http://dx.doi.org/10.1080/14330237.2014.997009]

[24] Abu-Hilal M, Al-Malkey H. Frame of reference and achievement across gender among Omani middle school students. Int J Educ Psychol Assess 2014; 16(1): 82-101

[25] Abu-Hilal M, Aldhafri S, Albahrani M, Kamali M. The Arab culture and the Arab self: Emphasis on gender.The Psychology of Asian Learners. Singapore: Springer Singapore 2016; pp. 125-38. [http://dx.doi.org/10.1007/978-981-287-576-1 8]

[26] Bouffard T, Marcoux MF, Vezeau C, Bordeleau L. Changes in selfperceptions of competence and intrinsic motivation among elementary schoolchildren. Br J Educ Psychol 2003; 73(Pt 2): 171-86.

[http://dx.doi.org/10.1348/00070990360626921] [PMID: 12828811]

[27] Abu-Hilal M. Arab-self characteristics: Studies in United Arab Emirates and Oman Alin: University Book House. 2017.

[28] Nagy G, Watt H, Eccles J, et al. The development of Students' mathematics self-concept in relation to gender: different countries, different trajectories? J Res Adolesc 2010; 20(2): 482-506. [http://dx.doi.org/10.1111/j.1532-7795.2010.00644.x]

[29] Almalky H. The psychometric properties of self-concept scale for grade seven, eight, and nine students in the Governorate of Albatenah South in the Sultanate of Oman [Master's thesis] Muscat: Sultan Qaboos University. 2012.

[30] Tabachnick B, Fidell L. Using multivariate statistics. 4th ed. Boston: Allyn and Bacon 2001.

[31] Cohen J. Statistical power analysis for the behavioral sciences. 2nd ed. Hillsdale, NJ: Lawrence Erlbaum Associates 1988.

[32] Marcotte D, Fortin L, Potvin P, Papillon M. Gender differences in depressive symptoms during adolescence: role of gender-typed characteristics, self-esteem, body image, stressful life events, and pubertal status. J Emot Behav Disord 2002; 10(1): 29-43. [http://dx.doi.org/10.1177/106342660201000104]

[33] Hudson L. Girls' self-esteem: Positive experiences and influences [Internet]. n.d. [cited 2 March 2019]. http://www.jlazyl.com/TexEdEx/ 
files/Positive_self.pdf

[34] Bair A, Steele JR, Mills JS. Do these norms make me look fat? The effect of exposure to others' body preferences on personal body ideals. Body Image 2014; 11(3): 275-81.

[http://dx.doi.org/10.1016/j.bodyim.2014.04.004] [PMID: 24958663]

[35] Thompson C, Russell-Mayhew S, Saraceni R. Evaluating the effects of a peer-support model: Reducing negative body esteem and disordered eating attitudes and behaviours in grade eight girls. Eat Disord 2012; 20(2): 113-26

[http://dx.doi.org/10.1080/10640266.2012.653946] [PMID: 22364343]

[36] Murray KM, Byrne DG, Rieger E. Investigating adolescent stress and body image. J Adolesc 2011; 34(2): 269-78.

[http://dx.doi.org/10.1016/j.adolescence.2010.05.004] [PMID: 2062 7369]

[37] Swalha A. A comparative study of self-concept among normal students and learning disability students in resources room in Amman capital. J Islam Univ Educ Psychol Stud 2013; 21(2): 219-58

[38] Leone JE, Fetro JV, Kittleson M, Welshimer KJ, Partridge JA, Robertson SL. Predictors of adolescent male body image dissatisfaction: Implications for negative health practices and consequences for school health from a regionally representative sample. J Sch Health 2011; 81(4): 174-84.

[http://dx.doi.org/10.1111/j.1746-1561.2010.00577.x] [PMID: 2139 2009]

[39] Parker P, Martin A, Marsh H. Factors predicting life satisfaction: A process model of personality, multidimensional self-concept, and life satisfaction. Aust J Guid Couns 2008; 18: 15-29. [http://dx.doi.org/10.1375/ajgc.18.1.15]
[40] Chetri S. Self-concept and achievement motivation of adolescents and their relationship with academic achievement. Int J Adv Res Technol 2014; 3(5): 236-5.

[41] Emanuel A, Adom E, Josphine B, Solomon F. Achievement motivation, academic self-concept and academic achievement among high school students. Eur J Res Reflect Educ Sci 2014; 2(2): 24-37.

[42] Alutaibi A. The effects of some demographic variables on achievement motivation among Kuwaiti university students. Arabic J. Adm Sci 1996; 3(2): 339-64.

[43] Nofel M. Differences in motivation to learn based on selfdetermination theory in a sample of educational colleges' students in Jordanian universities. J Alnajah Univ Hum Sci 2011; 25(2): 277-308.

[44] Al-Harthy I, Aldhafri S. The relationship among task-value, selfefficacy and academic achievement in Omani students at Sultan Qaboos University. Int Rev Soc Sci Hum 2014; 7(2): 15-22.

[45] Osman M, Al-Barwani Th, Al-Mekhlafi A, Abu Sheiba M. Gender Gap in Students Performance: Implications on the Labor Market and the Fabric of Society. 2014

[46] The national report of the International Mathematics and Science Study (TIMMS)/ grade 4. Muscat: Ministry of Education 2011 a.

[47] The national report of the International Mathematics and Science Study (TIMMS)/ grade 8. Muscat: Ministry of Education $2011 \mathrm{~b}$.

[48] Aldhafri S. The Parenting Styles in the Omani Families: Your Children, how to raise them?. Muscat: Alnahdhah Press 2014.

[49] Aldhafri S, Kazem A, Alzubiadi A, Yousif Y, Al-Bahrani M, Alkharusi H. Parenting styles as perceived by Omani children (classes 7 to 12 ) and their relationships with some demographic variables. Int J Res Educ 2011; 29: 1-26.

(C) 2019 Alrajhi et al.

This is an open access article distributed under the terms of the Creative Commons Attribution 4.0 International Public License (CC-BY 4.0), a copy of which is available at: https://creativecommons.org/licenses/by/4.0/legalcode. This license permits unrestricted use, distribution, and reproduction in any medium, provided the original author and source are credited. 